\title{
FAKTOR-FAKTOR YANG BERPENGARUH TERHADAP KEPUTUSAN PETANI DALAM ADOPSI INOVASI KALENDER TANAM TERPADU DI KECAMATAN GEDANGSARI KABUPATEN GUNUNG KIDUL
}

\section{AFFECTING FACTORS TOWARD FARMERS DECISIONS IN ADOPTION INNOVATIONS OF INTEGRATED IMPLANT CALENDAR IN SUB DISTRICT GEDANG SARI REGENCY OF GUNUNG KIDUL}

\author{
Muhammad lqbal Akbar, Suminah, Agung Wibowo \\ Program Studi Penyuluhan dan Komunikasi Pertanian, \\ Fakultas Pertanian, \\ Universitas Sebelas Maret Surakarta \\ Jl.Ir.Sutami No.36 A Kentingan Surakarta 57126 Telp./Fax (0271) 637457 \\ Email: muhammadiqbalakbar@student.uns.ac.id/Telp 081230019967
}

\begin{abstract}
Climate change is a natural phenomenon that has occurred at all levels of the continent or country, as well as specific location at sub-district level in relatively small area. Various weather and climate information services such as data afforded by government institutes, research institutes, and universities are far from the reach of farmers. This research aims to: study the influence of socio-economic factors, attitudes, access to communication media, needs and characteristics / nature of simultaneous or partial innovation toward farmers' decision in Integrated Katam innovation. The location of the study was deliberately determined in Tegalrejo and Watugajah because the village received the Integrated Katam program in Gedang Sari Sub-district, Gunung Kidul. The sampling method was done randomly using proportional random sampling with 50 people. Multiple linear regression is used as the data analysis. The results showed that: (1) characteristics of respondent farmers in socioeconomic factors were classified as moderate, attitudes wre classified as neutral, access of communication media were infrequently utilized, social needs level and characteristic / nature of innovation were quite appropriate; (2) socio-economic factors, attitudes, needs, access to communication media and characteristics / nature of innovation simultaneously have significant effects on the adopted decision of Integrated Katam innovation; (3) socioe-conomic factors, attitudes, needs and characteristics / nature of innovation have significant effects on decision to adopt innovation Integrated Katam partially while communication media access was not significant; (4) Decision making adoption of Integrated Katam innovation in Gedang Sari was moderate.
\end{abstract}

Keywords: Adoption Innovation; Decision; Integrated Implant Calender; Gedang Sari Subdistrict

Abstrak: Perubahan iklim merupakan gejala alam yang telah terjadi pada semua level baik benua atau negara, maupun spesifik lokasi pada level kecamatan dengan 


\section{Jurnal Agritexts Volume 42 Nomer 2 Oktober 2018}

area yang tidak begitu luas. Berbagai layanan informasi cuaca dan iklim seperti data yang diberikan oleh lembaga pemerintah, lembaga penelitian, dan perguruan tinggi masih jauh dari jangkauan petani. Kehadiran teknologi inovasi Sistem Informasi Kalender Tanam Terpadu (Katam Terpadu) memuat informasi penting seputar musim tanam padi, jagung dan kedelai. Penelitian ini bertujuan mengkaji pengaruh faktor sosial ekonomi, sikap petani terhadap inovasi, akses media komunikasi, kebutuhan dan faktor karakteristik inovasi secara parsial dan simultan terhadap pengambilan keputusan petani dalam adopsi inovasi Katam Terpadu. Lokasi penelitian ditentukan secara sengaja di desa Tegalrejo dan Watugajah karena desa tersebut yang menerima program Katam Terpadu di Kecamatan Gedang Sari Kabupaten Gunung Kidul. Metode pengambilan sampel dilakukan secara acak menggunakan proporsional random sampling dengan jumlah sampel 50 orang. Analisis data menggunakan regresi linier berganda. Hasil penelitian menunjukkan bahwa: (1) Karakteristik petani responden yaitu faktor sosial ekonomi tergolong sedang, sikap tergolong netral, akses media komunikasi tergolong jarang digunakan, kebutuhan pada tingkat kebutuhan sosial, dan karakteristik/sifat inovasi tergolong cukup sesuai; (2) Faktor sosial ekonomi, sikap, kebutuhan, akses media komunikasi dan karakteristik/sifat inovasi secara simultan berpengaruh signifikan terhadap keputusan adopsi inovasi Katam Terpadu; (3) Faktor sosial ekonomi, sikap, kebutuhan dan karakteristik/sifat inovasi secara parsial berpengaruh signifikan terhadap keputusan adopsi inovasi Katam Terpadu sedangkan akses media komunikasi tidak signifikan; (4) Pengambilan keputusan adopsi inovasi Katam Terpadu di Kecamatan Gedang Sari tergolong sedang.

Kata Kunci: Adopsi Inovasi; Kalender Tanam Terpadu; Kecamatan Gedang Sari; Keputusan

\section{PENDAHULUAN}

Sejarah Indonesia sejak masa kolonial sampai sekarang tidak dapat dipisahkan dari sektor pertanian dan perkebunan, karena sektor - sektor ini memiliki arti yang sangat penting dalam menentukan pembentukan berbagai realitas ekonomi dan sosial masyarakat di berbagai wilayah Indonesia. Pertanian merupakan salah satu sektor perekonomian yang menyediakan lapangan kerja tinggi namun rawan terhadap dampak negatif perubahan perilaku iklim (McCarl et al, 2001; Yohe and Tol, 2002; Stern, 2006). Djunedi (2016) menyebutkan bahwa menurut Jaffee et al (2008) dalam FAO (2011:16) ada delapan jenis risiko yang melekat pada rantai pasok sektor pertanian yaitu risiko cuaca/iklim, bencana alam, risiko lingkungan, risiko pasar, risiko logistik, risiko operasional, risiko kebijakan dan risiko politik. Perubahan iklim merupakan gejala alam yang telah terjadi pada semua level pada kawasan tertentu baik benua atau negara, maupun spesifik lokasi pada level kecamatan dengan area yang tidak begitu luas.

Sejak zaman dahulu petani di pulau jawa sudah menggunakan kalender mangsa. Kalender mangsa di dasarkan pada pola musim \& siklus alam (seperti kalender Masehi pada suatu tingkatan tertentu) bagi masyarakat agraris di Pulau Jawa. Bulan/mangsa bervariasi antara 23- 


\section{Akbar, Suminah, Wibowo, Adopsi Inovasi; Kalender,„,}

43 hari dikarenakan posisi Jawa yang sekitar 7 derajat di selatan. Namun kearifan lokal tersebut tidak dapat sepenuhnya dijadikan acuan dalam menetapkan awal musim tanam karena perubahan iklim yang terjadi dan semakin sulitnya menemukan indikator penanda musim. Fluktuasi curah hujan yang sangat dinamis akibat munculnya anomali iklim menyebabkan terjadinya pergeseran awal musim hujan dan musim kemarau. Dampak perubahan pola hujan dan pergeseran awal musim mengakibatkan perubahan waktu tanam yang dapat mempengaruhi maju mundurnya waktu tanam sehingga sangat menyulitkan petani yang telah terbiasa dengan kalender mangsa yang dilakukan. Kehadiran teknologi inovasi Sistem Informasi Kalender Tanam Terpadu (Katam Terpadu) memuat informasi penting seputar musim tanam padi, jagung dan kedelai. Katam Terpadu diharapkan dapat memberikan keyakinan dan kepastian kepada pengambil kebijakan, penyuluh, serta petani di daerah untuk menyusun kebutuhan definitif benih, jenis varietas, pupuk, dan mekanisasi pertanian. Hal tersebut berbeda untuk tanam padi pada lahan sawah tadah hujan, irigasi maupun pada lahan rawa. Banyak harapan yang tertumpu pada teknologi ini agar terjamin keberhasilan produksi padi pada tingkat kecamatan, kabupaten, provinsi dan nasional.

Sementara itu, berbagai layanan informasi cuaca dan iklim seperti data yang diberikan oleh lembaga pemerintah, lembaga penelitian, dan perguruan tinggi masih jauh dari jangkauan petani untuk dapat memanfaatkan informasi tersebut contohnya data iklim dari BMKG dan BPS. Kabupaten Gunung Kidul sejak tahun 2014 sudah melaksanakan sosialisasi dan penyuluhan mengenai Kalender Tanam Terpadu namun masih banyak petani yang belum sepenuhnya memanfaatkannya dengan baik berdasarkan wawancara dengan Dinas Pertanian. Penelitian ini kemudian dilakukan dengan adanya alasan bahwa petani menjadi bagian yang penting dalam proses adopsi inovasi, dikarenakan petani adalah pihak yang mengambil keputusan untuk menerima atau menolak inovasi yang ada. Pengambilan keputusan tentunya tidak hanya ditentukan oleh petani namun dipengaruhi oleh faktor-faktor dari petani dan sifat dari inovasi itu sendiri. Hal itulah yang coba dikaji dalam penelitian ini termasuk seberapa besar pengaruh faktorfaktor, baik intern atau pun ekstern, mempengaruhi pengambilan keputusan petani terhadap suatu inovasi, yaitu Katam Terpadu. Adapun tujuan 


\section{Jurnal Agritexts Volume 42 Nomer 2 Oktober 2018}

penelitian yang akan dilakukan adalah sebagai berikut: (1) Mengkaji pengaruh faktor sosial ekonomi, faktor sikap, faktor akses media komunikasi, faktor kebutuhan dan faktor karakteristik inovasi secara simultan dan parsial terhadap pengambilan keputusan petani dalam adopsi inovasi Katam Terpadu.

\section{METODE PENELITIAN}

Penelitian ini menggunakan metode penelitian deskriptif kuantitatif, sedangkan teknik yang digunakan adalah teknik survey. Pemilihan lokasi dilakukan secara sengaja purposive. Penelitian dilakukan di Kabupaten Gunung Kidul dengan pertimbangan bahwa Kabupaten Gunung Kidul merupakan salah satu dari Kabupaten di Yogyakarta dan salah satu dari beberapa kabupaten di seluruh Indonesia yang mendapatkan program Kalender Tanam Terpadu namun produktivitasnya terendah. Populasi yang digunakan dalam penelitian ini adalah petani padi/palawija di Kabupaten Gunung kidul yang sudah mendapatkan sosialisasi atau penyuluhan mengenai Kalender tanam terpadu. Memilih kecamatan Gendang Sari karena kecamatan tersebut memiliki luas lahan sawah tertinggi yang ditanami Padi di Kabupaten Gunung Kidul. Lalu dipilih 2 desa yang memiliki kelompok tani dengan nilai ke aktifan tertinggi dan terendah. Sampel yang dipilih yaitu kelompok tani Selo Kencono II di desa Tegalrejo dan kelompok tani Ngudi Makmur I di desa Watugajah, dikarenakan kelompok tani tersebut sudah mendapatkan sosialisasi mengenai Kalender Tanam Terpadu dan memiliki komoditas unggulan yaitu padi/palawija sebagai perwakilan dari Kecamatan Gedang Sari. Jenis data yang digunakan dalam penelitian ini adalah data primer dan sekunder. Teknik pengumpulan data dalam penelitian ini adalah dengan menggunakan teknik wawancara, observasi dan dokumentasi. Penelitian ini menggunakan uji regresi linier berganda.Persamaan analisis regresi yang dipakai dalam penelitian ini adalah sebagai berikut:

$$
\begin{aligned}
& Y=\alpha+b_{1} X_{1}+b_{2} X_{2}+b_{3} X_{3}+ \\
& b_{4} X_{4} \ldots \ldots . .+\varepsilon \ldots \ldots \ldots \ldots \ldots \ldots \ldots . .(1) \\
& \text { Keterangan : } \\
& Y: \text { Keputusan adopsi inovasi } \\
& X_{1}: \text { Sosial ekonomi } \\
& X_{2}: \text { Sikap } \\
& X_{3}: \text { Akses media komunikasi } \\
& X_{4}: \text { Kebutuhan } \\
& X_{5}: \text { Karakteristik/sifat inovasi }
\end{aligned}
$$

\section{HASIL DAN PEMBAHASAN}

Menurut data Kabupaten Gunung Kidul dalam Angka Tahun 2016, Secara geografis Kabupaten Gunung Kidul berada diantara koordinat $110^{\circ} 21^{\prime}-110^{\circ} 50^{\prime}$ Bujur Timur dan $7^{\circ} 46^{\prime}-8^{\circ} 09^{\prime}$ Lintang 


\section{Akbar, Suminah, Wibowo, Adopsi Inovasi; Kalender,„,}

Selatan. Wilayah administratif Kabupaten Gunung Kidul terbagi menjadi 18 kecamatan, 118 desa. Diketahui bahwa luas kecamatan Gedang Sari 68,14 ha. Desa Tegalrejo dan Watugajah memiliki masing-masing 14,70\% (10.02 ha) dan 11,68\% (7.96 ha) dari total wilayah kecamatan Gedangsari. Jumlah penduduk lakilaki di Kecamatan Gedangsari 17.357 dan perempuan 18.069 dengan total jumlah penduduk sebanyak 35.426 . Luas panen padi sawah dan ladang kecamatan Gedang Sari sebanyak
$1817 \mathrm{Ha}$. Total produksi padi sawah dan ladang yaitu $11.536,64$ ton. Desa Watugajah dan Tegalrejo menyumbang total produksi 747,43 ton dan 997,88 ton.

\section{Faktor-Faktor Yang Mempangaruhi Keputusan}

Faktor-faktor yang mempengaruhi keputusan adopsi inovasi meliputi faktor sosial ekonomi, faktor sikap, faktor akses media komunikasi, faktor kebutuhan dan faktor karakteristik inovasi

Tabel 1. Distribusi Responden Berdasarkan Faktor-faktor yang Mempengaruhi Keputusan Adopsi Inovasi.

\begin{tabular}{|c|c|c|c|}
\hline \multicolumn{4}{|c|}{ Faktor Sosial Ekonomi } \\
\hline Kategori & Skor & Jumlah & Presentase(\%) \\
\hline Sedang & $7,9-10,2$ & 36 & 72 \\
\hline \multicolumn{4}{|c|}{ Sikap Petani Terhadap Inovasi } \\
\hline Kategori & Skor & Jumlah & Presentase(\%) \\
\hline Netral & $28,7-37,4$ & 35 & 70 \\
\hline \multicolumn{4}{|c|}{ Akses Media Komunikasi } \\
\hline Kategori & Skor & Jumlah & Presentase(\%) \\
\hline Jarang & $7,3-10,4$ & 20 & 40 \\
\hline \multicolumn{4}{|c|}{ Kebutuhan } \\
\hline Kategori & Skor & Jumlah & Presentase(\%) \\
\hline Kebutuhan sosial & 23.5-30.6 & 29 & 58 \\
\hline
\end{tabular}

Sumber: Analisis Data Primer, 2017

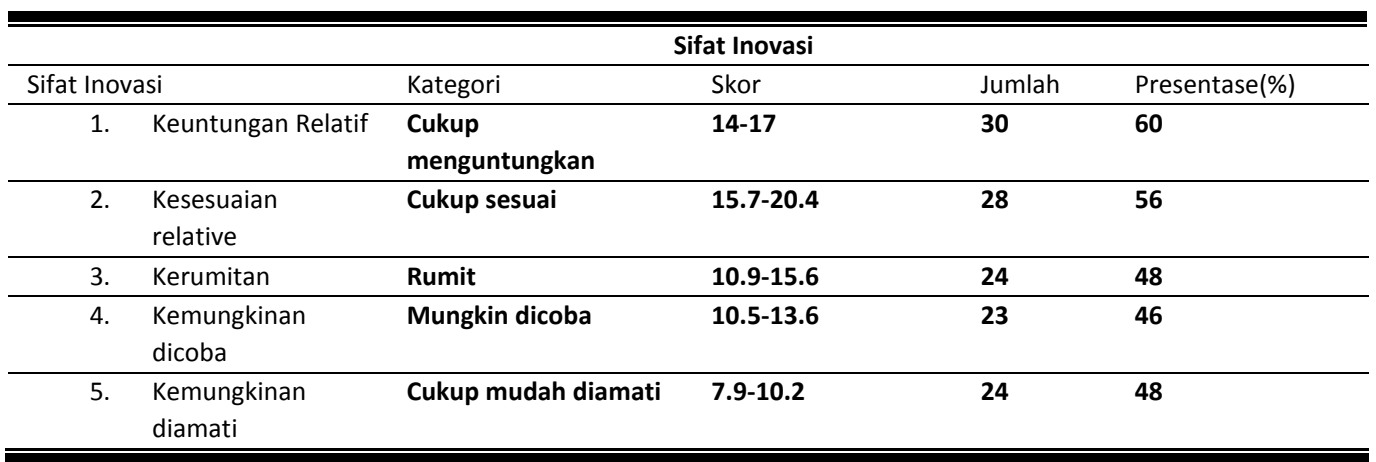

Sumber: Analisis Data Primer, 2017 


\section{Jurnal Agritexts Volume 42 Nomer 2 Oktober 2018}

Berdasarkan Tabel 1 dapat dilihat bahwa responden dalam penelitian memiliki keadaan sosial ekonomi yang mayoritas sedang berjumlah 36 orang. Hasil diatas menunjukkan bahwa sosial ekonomi yang ditempati individu atau keluarga dengan ukuran rata-rata yang umum berlaku di masyarakat tentang kepemilikan kultural, pendapatan dan partisipasi dalam aktifitas kelompok dari komunitasnya tergolong sedang. Sikap terhadap inovasi yang mayoritas netral dengan berjumlah 35 orang. Perasaan (afeksi), pemikiran (kognisi), dan predisposisi tindakan (konasi) dari petani responden yang netral dengan adanya Katam Terpadu dikarenakan menurut petani, Katam Terpadu memiliki manfaat yang cukup baik terutama pada rekomendasi varietas dan pediksi sifat hujan yang sesuai dengan keadaan dan kondisi lingkungan. Akses media komunikasi yang mayoritas jarang dengan jumlah 20 orang.

Berdasarkan kondisi yang terjadi di kedua desa tersebut, media komunikasi yang jarang digunakan yaitu handphone, internet, koran dan media cetak lainnya. Kebutuhan responden dalam penelitian mayoritas pada tahap kebutuhan sosial sebanyak 29 orang. Artinya masyarakat sudah merasa cukup pada kebutuhan fisik dan rasa aman dikarenakan inovasi baru seperti Katam Terpadu. Sifat inovasi dari program Katam Terpadu dilihat dari keuntungan relatif sebagian besar mengatakan cukup menguntungkan dengan jumlah 30 orang, sifat kesesuaian relatif sebagian besar mengatakan cukup sesuai dengan jumlah 28 orang, sifat kerumitan sebagian besar mengatakan rumit dengan jumlah 24 orang, sifat kemungkinan dicoba sebagian besar mengatakan mungkin dicoba dengan jumlah 23 orang, dan sifat kemungkinan diamati sebagian besar mengatakan cukup mudah untuk diamati dengan jumlah 24 orang.

\section{Keputusan Adopsi Inovasi}

Kompetensi penyuluh merupakan kemampuan yang harus dimiliki seseorang dalam melakukan suatu pekerjaan dengan tujuan tertentu. Berikut ini penjelasan terkait kompetensi penyuluh: 
Akbar, Suminah, Wibowo, Adopsi Inovasi; Kalender,,,

Tabel 2. Distribusi Responden Berdasarkan Pengambilan keputusan petani terhadap adopsi inovasi Katam Terpadu di Kabupaten Gunung Kidul

\begin{tabular}{|c|c|c|c|}
\hline \multicolumn{4}{|c|}{ Keputusan Adopsi Inovasi } \\
\hline Skor & Kategori & Jumlah (Orang) & Prosentase (\%) \\
\hline $14-17$ & Sedang & 30 & 60 \\
\hline \multicolumn{4}{|c|}{ Keberlanjutan Keputusan Adopsi Inovasi } \\
\hline Kategori & Jumlah & \multicolumn{2}{|c|}{ Prosentase (\%) } \\
\hline Sudah menggunakan & 30 & \multicolumn{2}{|c|}{60} \\
\hline Belum menggunakan & 20 & \multicolumn{2}{|c|}{40} \\
\hline Jumlah & 50 & \multicolumn{2}{|c|}{100} \\
\hline Akan menggunakan & 15 & \multicolumn{2}{|c|}{75} \\
\hline Tidak akan menggunakan & 5 & \multicolumn{2}{|c|}{25} \\
\hline Jumlah & 20 & \multicolumn{2}{|c|}{100} \\
\hline
\end{tabular}

Sumber: Analisis Data Primer, 2017

Berdasarkan Tabel 2 dapat dilihat bahwa responden sebagian besar sudah menggunakan kalender tanam terpadu sebanyak 30 responden dan sisanya belum menggunakan sejumlah 20 responden. Selanjutnya dari 20 responden yang belum menggunakan mengatakan akan menggunakan sebanyak 15 responden dan tidak akan menggunakan sebanyak 5 responden. hasil diatas dapat diketahui bahwa keputusan petani untuk menerima inovasi Katam Terpadu cukup tinggi dikarenakan banyak anggota petani dari masingmasing kelompok tani yang menggunakan varietas yang direkomendasikan seperti padi Ciherang dan Ir 64, selain itu juga ada beberapa petani dari masing-masing yang mengikuti rekomendasi penggunaan pupuk dan sebagian besar juga sudah mengikuti waktu tanam serentak yang sudah di rekomendasikan. Hal tersebut juga didukung dengan sikap petani dan kebutuhan akan inovasi yang cukup tinggi dikarenakan prediksi dan rekomendasi yang sesuai dengan keadaan lingkungan dan perubahan musim yang tidak menentu sehingga petani lebih memilih Katam Terpadu daripada kalender mangsa.

\section{Analisis Regresi Linier Berganda}

Model Persamaan Regresi Faktor yang Mempengaruhi Kaputusan Adopsi Inovasi

$Y=-4,2326+0,29818 X 1+0,14205$

$X 2-0,13631 X 3+0,23052 X 4+$

$0,10205 \times 5$

Keterangan:

$Y=$ Pengambilan Keputusan Petani Dalam Adopsi Inovasi Kalender Tanam Terpadu

$\mathrm{X} 1=$ Faktor Sosial Ekonomi

$\mathrm{X} 2=$ Faktor Sikap Petani

X3 $=$ Akses Media Komunikasi

$\mathrm{X} 4=$ Kebutuhan Petani Terhadap Inovasi

X5= Sifat inovasi 


\section{Jurnal Agritexts Volume 42 Nomer 2 Oktober 2018}

Uji Koefisien Determinasi

Koefisien determinasi

digunakan sebagai ukuran untuk menyatakan kecocokan garis regresi yang diperoleh.

Tabel 3.Hasil Uji Model Summary Nilai Adjusted R Square

\begin{tabular}{rrr}
\hline \hline Model & $R$ Square & Adjusted $R$ Square \\
\hline 1 & .728 & .6971 \\
\hline \hline
\end{tabular}

Sumber : Analisis Data Primer 2017

Berdasarkan Tabel 3 dapat dilihat bahwa nilai R2 adalah 0,728. Hal ini berarti bahwa variabel independen (faktor sosial ekonomi, faktor sikap, akses akses media komunikasi, kebutuhan dan sifat inovasi) dapat menjelaskan variabel dependen (pengambilan keputusan petani terhadap adopsi inovasi katam terpadu) sebesar 72,8\%, sedangkan sisanya $27,2 \%$ diterangkan oleh faktor lain yang tidak diteliti seperti luas lahan, pengalaman ber- usahatani, keberanian mengambil risiko, peran penyuluh dan keaktifan petani dalam kelompok berdasarkan perbandingan dengan penelitian terdahulu.

\section{Uji Koefisien Regresi Secara Seren- tak (Uji F)}

Uji $F$ atau uji koefisien regresi secara serentak, digunakan untuk mengetahui pengaruh variabel independen secara serentak terhadap variabel dependen, apakah pengaruhnya signifikan atau tidak.

Tabel 4 Hasil Uji Simultan (Uji F) terhadap Variabel Y (Keputusan Adopsi Inovasi)

\begin{tabular}{lrrr}
\hline & \multicolumn{1}{c}{ Analysis Of Variance - From Mean } & F \\
\hline & Sum of Square & Mean Square & 23,550 \\
\hline Regression & 332,60 & 66,519 & P-Value \\
Residu & 124,28 & 2,8246 & $\mathbf{0 . 0 0 0}$ \\
\hline Total & 456,88 & 9,3241 & \\
\hline \hline
\end{tabular}

Sumber : Analisis Data Primer Tahun 2017

Hasil uji F yang ditunjukan pada Tabel 4 didapatkan hasil nilai P-value $F$ hitung sebesar 0.000 dan tingkat signifikasi $(\alpha=0,05)$. Jadi, $p$ value $\leq \alpha$ atau $0,000 \leq 0,05$. Berdasarkan perbandingan tersebut maka $\mathrm{HO}$ ditolak dan $\mathrm{H} 1$ diterima, yang berarti variabel independen faktor sosial ekonomi (X1), faktor sikap (X2), akses media komunikasi (X3), kebutuhan (X4) dan sifat inovasi (X5) berpengaruh signifikan secara bersamasama terhadap variabel dependen pengambilan keputusan terhadap adopsi inovasi Katam Terpadu (Y). 
Akbar, Suminah, Wibowo, Adopsi Inovasi; Kalender,,,

\section{Uji Parsial (Uji t)}

Uji t digunakan untuk menguji pengaruh faktor sosial ekonomi (X1), faktor sikap (X2), akses media komunikasi (X3), kebutuhan (X4) dan sifat inovasi (X5) terhadap variabel dependen pengambilan keputusan adopsi inovasi Katam Terpadu (Y)

Tabel 5 Hasil Uji Parsial (Uji t) terhadap Variabel Y (Keputusan adopsi inovasi)

\begin{tabular}{|c|c|c|c|c|}
\hline \multirow{2}{*}{$\begin{array}{l}\text { Model } \\
\text { Variable }\end{array}$} & \multicolumn{2}{|l|}{ OIS } & \multicolumn{2}{|l|}{ Depvar* } \\
\hline & Koef. Reg & P-value & Koef Reg & P-value \\
\hline $\begin{array}{l}\text { Faktor Sosial Ekonomi } \\
\text { (X1) }\end{array}$ & 0,29982 & 0,165 & 0,29818 & 0,034 \\
\hline Faktor Sikap (X2) & 0,13881 & 0,159 & 0,14205 & 0,005 \\
\hline $\begin{array}{l}\text { Faktor Akses Media } \\
\text { Komunikasi (X3) }\end{array}$ & $-0,99897$ & 0,444 & $-0,13631$ & 0,120 \\
\hline Faktor Kebutuhan (X4) & 0,21757 & 0,005 & 0,23052 & 0,000 \\
\hline $\begin{array}{l}\text { Faktor Sifat Inovasi } \\
\text { (X5) }\end{array}$ & 0,937 & 0,067 & 0,10205 & 0,004 \\
\hline $\begin{array}{l}\text { Keterangan : } \\
\text { Depvar* = Model Heter } \\
\alpha=0,05(95 \%)\end{array}$ & & & & \\
\hline
\end{tabular}

Sumber : Analisis Data Primer Tahun 2017

Pengaruh Faktor Sosial Ekonomi (X1)

Terhadap Keputusan Adopsi Inovasi

Kalender Tanam Terpadu

Hasil diatas sesuai dengan Mardikanto (2009) dan Soekartawi (1988) menyatakan bahwa petani dengan tingkat sosial ekonomi yang semakin tinggi umumnya akan semakin cepat mengadopsi inovasi. Kondisi di lapangan pada penelitian ini menunjukkan bahwa keadaan sosial ekonomi yang cukup tinggi dari para petani menjadikan adopsi inovasi yang cukup tinggi pula, sebaliknya beberapa petani yang memiliki pendapatan cukup rendah juga masih urung untuk mengadopsi karena kebanyakan masih berpikiran kurang menguntungkan.
Pengaruh Faktor Sikap (X2) Terhadap Adopsi Inovasi Kalender Tanam Terpadu

Hasil penelitian menunjukkan bahwa petani bersikap netral dengan adanya inovasi Katam Terpadu, hal ini sesuai dengan penelitian Azwar (2013). bahwa semakin tinggi sikap dan semakin baik sikap terhadap inovasi maka mempercepat adanya adopsi inovasi tersebut. Berdasarkan keadaan di lapangan banyak petani memiliki pemikiran, kesukaan terhadap Katam Terpadu karena dianggap sudah memberikan manfaat nyata dalam pertanian, salah satunya rekomendasi varietas padi yang sesuai dengan keadaan tanah dan musim sehingga meningkatkan pro- 


\section{Jurnal Agritexts Volume 42 Nomer 2 Oktober 2018}

duksi padi di Kecamatan Gedang Sari. Namun beberapa diantaranya juga memberikan sikap kurang baik terhadap rekomendasi pupuk, petani lebih memilih menggunakan pupuk sesuai takaran yang biasanya mereka pakai.

Pengaruh Faktor Akses Media Komunikasi (X3) Terhadap Adopsi Inovasi Kalender Tanam Terpadu

Hal tersebut tidak sesuai dengan hasil penelitian Muhtadi (1999), bahwa akses media komunikasi adalah sebuah perantara dalam menyampaikan sebuah informasi dari komunikator kepada komunikan yang bertujuan agar efisien dalam menyebarkan informasi atau pesan sehingga mempercepat adanya adopsi inovasi. Dari hasil penelitian didapatkan bahwa akses media komunikasi tidak berpengaruh secara signifikan dikarenakan di lokasi penelitian jarang sekali petani mengakses informasi lewat akses media komunikasi elektronik, kebanyakan masyarakat mendapatkan informasi melalui penyuluhan ataupun dari petani lain serta rapat kelompok tani yang diadakan satu bulan sekali.

Pengaruh Faktor Kebutuhan Petani Terhadap Inovasi (X4) Terhadap Adopsi Inovasi Kalender Tanam Terpadu

Hasil tersebut sesuai dengan kebutuhan menurut Murray (1938) adalah sebuah konstruk yang menun- jukkan sebuah dorongan dalam wilayah otak yang mengatur berbagai proses seperti presepsi, pikiran, dan tindakan dengan maksud untuk mengubah kondisi yang ada dan tidak memuaskan. Kebutuhan terhadap inovasi tertentu berkenaan dengan kebutuhan nyata yang dapat dilihat atau dirasakan sehingga seseorang dapat merasakan bahwa inovasi itu benar-benar dapat membantu memenuhinya. Hal itu terjadi karena petani cukup membutuhkan informasi dari Katam Terpadu seperti varietas apakah yang direkomendasikan, penggunaan pupuk dan waktu tanam yang sesuai, hal tersebut juga dipengaruhi oleh musim yang saat ini tidak menentu sehingga petani lebih memilih informasi seperti Katam Terpadu. Namun beberapa kebutuhan seperti rekomendasi pupuk yang diberikan Katam Terpadu beberapa kali juga bermasalahan dengan ketersediaan pupuk pada toko tani yang tidak mencukupi, tidak hanya itu beberapa kali varietas unggul yang direkomendasikan juga kurang laku di pasaran, meskipun produktivitasnya tinggi petani lebih memilih menggunakan varietas lama yang laku dipasaran.

Pengaruh Faktor Sifat Inovasi (X5) Terhadap Adopsi Inovasi Kalender Tanam Terpadu

Hasil penelitian sesuai dengan pendapat Indraningsih (2011) bahwa Katam Terpadu mempunyai kelebi- 


\section{Akbar, Suminah, Wibowo, Adopsi Inovasi; Kalender,,,}

han yaitu dibutuhan oleh petani karena memuat informasi pertanian yang terbaru, mempunyai keselarasan dengan petani, dibuktikan dengan varietas dan musim tanam yang sesuai, sedangkan untuk pupuk, petani masih sedikit demi sedikit menyesuaikan. Inovasi Katam Terpadu cukup terjangkau jika disebarkan melalui penyuluhan, namun tidak jika melalui media elektronik seperti android dan sms dikarenakan banyak petani yang kesulitan dalam mengaksesnya disebabkan ketidakmampuan pengoprasiannya dan keadaan wilayah yang jauh dari kota sehingga mengalami susah signal/ jaringan.

Berdasarkan hasil di lapangan, Katam Terpadu memiliki keunggulan dalam segi keuntungan relatif berupa varietas rekomendasi, awal tanam dan pupuk yang cukup sesuai untuk digunakan. Namun dari beberapa petani ada yang menggunakan varietas lama, dikarenakan varietas tersebutlah yang laku di pasaran meskipun varietas baru/rekomendasi lebih produktif. Di Kecamatan Gedangsari biasanya petani juga lebih memilih penggunaan pupuk seperti biasanya dengan takaran petani sendiri karena kadang-kadang pupuk yang direkomendasikan Katam Terpadu tidak ada di toko tani/toko pupuk. Tingkat kerumitan program Katam Terpadu yang dirasakan petani di Kabupaten Gunung Kidul adalah dalam hal pencarian informasinya yang rumit jika dalam betuk website/aplikasi android dan kebanyakan petani dengan usia tua hanya bisa mengandalkan dari sosialisasi/ penyuluhan pertanian, kebanyakan masih berpikiran bahwa Katam Terpadu lebih rumit dibandingkan dengan kalender mangsa.

Sedangkan untuk tingkat ketercobaan dan keteramatan bagi petani di Kecamatan Gedang Sari merasa mudah karena hasilnya bisa diketahui secara langsung dilapangan. Imbas jika inovasi tersebut terjangkau oleh kemampuan finansial petani, sederhana, tidak rumit, mudah dicoba, mudah untuk diamati maka kelangsungan inovasi tersebut akan terus terjaga. Semakin tinggi kesesuaian sifat inovasi dengan apa yang diharapkan petani maka semakin cepat dan semakin tinggi tingkat pengambilan keputusan petani terhadap adopsi inovasi Katam Terpadu di Kecamatan Gedang sari.

\section{KESIMPULAN DAN SARAN}

\section{Kesimpulan}

Berdasarkan hasil analisis: Karakteristik responden di Kecamatan Gedang Sari Kabupaten Gunung Kidul yaitu: (a) Faktor sosial ekonomi tergolong sedang (b) Faktor sikap petani terhadap inovasi tergolong netral (c) Akses media komunikasi petani tergolong jarang (d) Kebutuhan petani responden mayoritass 


\section{Jurnal Agritexts Volume 42 Nomer 2 Oktober 2018}

berada pada tingkat kebutuhan sosial dan (e) Sifat inovasi program Katam Terpadu tergolong cukup sesuai.

Pengambilan keputusan petani di Kecamatan Gedang Sari Kabupaten Gunung Kidul terhadap adopsi inovasi Katam Terpadu yaitu tergolong sedang.

Pengaruh karakteristik responden terhadap pengambilan keputusan petani pada pelaksanaan program Katam Terpadu di Kabupaten Gunung Kidul adalah sebagai berikut: (a) Faktor sosial ekonomi, faktor sikap, faktor media komunikasi, faktor kebutuhan dan sifat inovasi secara bersama-sama berpengaruh signifikan terhadap keputusan adopsi inovasi petani; (b) Secara parsial kebutuhan, faktor sosial ekonomi, faktor sikap, dan sifat inovasi berpengaruh signifikan terhadap keputusan adopsi inovasi petani sedangkan faktor media komunikasi tidak berpengaruh secara signifikan. (c) Faktor sosial ekonomi, faktor sikap, faktor kebutuhan dan faktor sifat inovasi mempunyai arah pengaruh yang positif, sedangkan faktor media komunikasi mempunyai arah pengaruh yang negatif terhadap keputusan adopsi inovasi petani terhadap program Katam Terpadu.

\section{Saran}

Berdasarkan hasil penelitian yang telah dilakukan, maka saran yang dapat diberikan adalah:
Pemerintah (BPTP) sebaiknya menggunakan media cetak untuk memberikan informasi Katam Terpadu seperti booklet/leaflet pada awal sebelum musim tanam

Sikap petani terhadap program Katam Terpadu harusnya mendapat perhatian lebih dari pemerintah, karena dengan mengetahui sikap petani terhadap suatu program maka dapat membantu pemerintah dalam mengevaluasi suatu program yang sedang dilaksanakan dan bagaimana perbaikan yang akan dilakukan kedepannya.

Proses pengadopsiannya harus disertai pendampingan penyuluh secara terus-menerus sehingga semakin lama semakin terbiasa berusaha tani padi dengan rekomendasi Katam Terpadu.

Sikap berpengaruh signifikan terhadap keputusan petani pada adopsi inovasi Katam Terpadu. Oleh sebab itu afeksi, kognisi dan konasi harus selalu ditingkatkan dan berpikir positif/melihat kelebihan dari inovasi tersebut terlebih dahulu, sehingga inovasi tersebut bisa berjalan dengan baik.

Petani sebaiknya tetap memperhatikan musim yang saat ini tidak menentu yang bisa menyebabkan berbagai masalah pertanian dan berakibat terjadinya gagal panen, informasi tersebut bisa diakses melalui Katam Terpadu. Berdasarkan 


\section{Akbar, Suminah, Wibowo, Adopsi Inovasi; Kalender,,,}

penelitian yang telah dilakukan, maka saran yang dapat diberikan :

\section{DAFTAR PUSTAKA}

Allan R. 2000. ENSO and Climatic Variability in The Past 150 years, in. ENSO: Multiscale Variability

Asep, Saepul Muhtadi. 1999. Jurnalistik Pendekatan Teori dan Praktek. Jakarta: Logos Wacana IImu. Hal 173.

Azwar, Saifuddin, M.A. 2013. Sikap Manusia Teori dan Pengukurannya. Yogyakarta: Pustaka Pelajar. Hal 5

Djunaedi, Achmad. 2016. Spatial Patternsof Agriculture and Industrial Sector Linkages and Its Implication On Interregional. Collaboration A Study Of Kedungsepur Area. Hal 5-13.

FAO. 2011. Climate change and food security: A framework document. Food and agriculture organization of the united nations, rome.

Indraningsih, K. S. 2011. Pengaruh Penyuluhan Terhadap Kepu- tusan Petani dalam Adopsi Inovasi Teknologi Usaha Tani Terpadu. Jurnal Agro Ekonomi. Volume 29 No.1, Mei 2011: 124.

Mardikanto. 2009. Sistem Penyuluhan Pertanian. Surakarta: Sebelas Maret University Press.

Naylor RL, Falcon W, Wada N, Rochberg D. 2002. Using ElNiño Southern Oscillation climate data to improve food policy planning in Indonesia. Bull Indon Econ Stud 38: 75-91.

Soekartawi. 1988. Prinsip Dasar Komunikasi Pertanian. Universitas Indonesia Press. Jakarta.

Stern, N., S. peters, V. bakhshi, A. bowen, C. Cameron, S. Catovsky, D. Crane, S. Cruickshank, S. Dietz, N. Edmonson, S.-I. Garbett, L. Hamid, G. Hoffman, D. Ingram, B. Jones, $\mathrm{N}$. Patmore, H. Radcliffe, R. Sathiyarajah, M. Stock, C. Tylor,, T. Vernon, H. Wanjie, and D. Zenghelis. 2006. Stern Review: the economics of climate change, 